\title{
Utilization of palliative radiotherapy for bone metastases near end of life in a population-based cohort
}

\author{
Manpreet S. Tiwana ${ }^{1,2}$, Mark Barnes ${ }^{1}$, Andrew Kiraly ${ }^{2}$ and Robert A. Olson 1,2,3*
}

\begin{abstract}
Background: Palliative radiotherapy (PRT) can significantly improve quality of life for patients dying of cancer with bone metastases. However, an aggressive cancer treatment near end of life is an indicator of poor-quality care. But the optimal rate of overall palliative RT use near the end of life is still unknown. We sought to determine the patterns of palliative radiation therapy (RT) utilization in patients with bone metastases towards their end of life in a population-based, publicly funded health care system.
\end{abstract}

Methods: All consecutive patients with bone metastases treated with RT between 2007 and 2011 were identified in a provincial Canadian cancer registry database. Patients were categorized as receiving RT in the last 2 weeks, 2-4 weeks, or $>4$ weeks before their death. Associations between RT fractionation utilization by these categories, and patient and provider characteristics were assessed through logistic regression.

Results: Of the 16,898 courses 1734 (10.3) and 709 (4.2\%) were prescribed to patients in the last 2-4 weeks and $<2$ weeks of their life, respectively. Primary lung (8\%) and gastrointestinal (6.9\%) cancers received palliative RT more commonly in the last 2 weeks of life (OR 3.72 [2.86-4.84] \& 3.33 [2.42-4.58] respectively, $p<0.001)$. Among the 709 patients who received RT in the last 2 weeks of life, 350 (49), 167 (24), and 127 (18\%) were for spine, pelvis, and extremity metastases, respectively. RT was prescribed most frequently to spine (5\%) and extremity (4\%) metastases $p<0.001$ in the last two weeks of life, though only varied between $1 \%$ (sternum) and $5 \%$ (spine) by site of metastases. Single fraction RT was prescribed more commonly in the last 2 weeks of life $(64.2 \%)$, compared to individuals who received RT 2-4 weeks (54.5), and $>4$ weeks $(47.9 \%)$ before death $(p<0.001)$.

Conclusions: This population-based analysis found that only $4 \%$ of patients with bone metastases received radiation therapy during the last 2 weeks of their life in our population-based, publicly funded program, though it was significantly higher in patients with lung cancer and those with metastases to the spine or extremity. Appropriately, use of multiple fractions palliative RT was less common in patients closer to death.

Keywords: Bone metastases, Palliative, Radiation therapy, End of life

\section{Background}

Approximately half of prescribed radiotherapy (RT) is delivered with palliative intent across North America $[1,2]$. Palliative RT has numerous indications, and primarily includes the treatment of painful bone metastases [2]. Palliative RT for bone metastases provides successful pain relief, preservation of function,

\footnotetext{
* Correspondence: rolson2@bccancer.bc.ca

'BC Cancer Agency-Centre for the North, Prince George, Canada

${ }^{2}$ University of Northern British Columbia, Prince George, Canada

Full list of author information is available at the end of the article
}

and maintenance of skeletal integrity with minimal risk of serious side effects $[3,4]$.

Palliative RT for bone metastases reduces pain in the majority of patients, though often takes several weeks [5]. The use of palliative RT use in the final weeks of life of therefore may have limited clinical use and may actually impair quality of life for patients and their families near the end of life [5].

The optimal rate of palliative RT use near the end of life is still unknown [5]. The use of systemic therapies at the end of life has been extensively studied, and same is 
warranted for optimal rate of palliative RT usage in such patients $[6,7]$. An overly aggressive cancer treatment at the end of life may be an indicator of poor-quality care [6-8]. The total palliative RT dose, the dose per fraction and the technique of irradiation use may vary with the treatment aim in patients with bone metastases [9].

British Columbia $(\mathrm{BC})$ provides $100 \%$ of the radiation therapy in the province as a, publicly-funded service with no direct costs to patients. We previously published initial results demonstrating variation in $\mathrm{RT}$ prescribing practices for bone metastases in $\mathrm{BC}$, where we demonstrated an association between fractionation and prognosis [10]. The primary objective of this current study is to explore the patterns of RT usage in patients with bone metastases towards their end of life. Understanding the patterns of palliative RT in patients with bone metastases will help us measure our quality and consistency of end of life care across the province.

\section{Methods}

\section{Study design and cohort selection}

This population-based retrospective study used administrative data to define a cohort of patients who received palliative RT for bone metastases during 2007 through 2011. This study was approved by the joint University of British Columbia and BC Cancer Agency (BCCA) Research Ethics Board.

\section{Data source and extraction}

Patient data was extracted through the BCCA Cancer Agency Information System. The RT parameters were retrieved from BCCA's RT database [11] and included site of RT, date of RT, dose, and fractionation. These databases were used to abstract patient, provider and treatment characteristics. Patient chart reviews, and review of RT plans where necessary, were performed to identify the various patient and physician related parameters associated with palliative RT in bone metastases. The provincial radiation therapy facilities up to 2011 were located in Abbotsford, Kelowna, Surrey, Vancouver \& Victoria.

\section{Patient and treatment variables}

The patients who received RT for bone metastases at the BC Cancer Agency from 2007 to 2011 were included in the analysis. The commonly occurring primary tumour sites were categorized as prostate, breast, lung, lymphoma, and gastro-intestinal (GI). The key sites of skeletal metastases were classified as spine, pelvis, extremity, rib, sternum, and 'skull', the latter of which included orbit and jaw. For descriptive analyses, RT fractionation was classified into single fraction (SF) or multiple fractions (MF).

\section{Statistical analysis}

Time to death was calculated from last course of palliative RT. This time interval (in weeks) was categorized into three groups : $<2$, and 2-4, and $>4$ weeks. Association between these categories and the variables was analyzed through descriptive statistics, and chi-square test. Subsequently, univariable and multivariable linear regression analyses were performed to assess these associations. $P$ values were two-sided, and values less than .05 were considered statistically significant. Analyses were conducted using the SPSS statistical software package, version 19.0 (Chicago, IL).

\section{Results}

A total of 16,898 courses of palliative RT were delivered to 8301 patients from 2007 to 2011 . Baseline patient and treatment related factors are summarized Table 1, and have also been presented in an earlier publication ${ }^{10}$. The median survival for the entire cohort was 18 weeks (95 \% CI 17.49-18.51).

Of the 16,898 courses 1734 (10.3) and 709 (4.2\%) were prescribed to patients in the last 2-4 weeks and $<2$ weeks of their life, respectively (Table 1 ). Table 2 highlights the univariate analysis on the utilization of palliative RT in the last 2 weeks of life. Single fraction RT was prescribed more frequently in patients with a shorter time from RT to end of life (Fig. 1).

Multivariable logistic regression is presented in Table 3, demonstrating a significant association between use of RT in the last 2 weeks of life and site of primary, site of metastases, and BCCA Centre (Table 3). Lung cancer patients $(p<0.001)$, and those receiving $\mathrm{RT}$ to spinal metastases $(p<0.001)$, were more likely to receive $\mathrm{RT}$ in the last 2 weeks of life (Table 3 ).

\section{Discussion}

We demonstrated that 4 and $10 \%$ of palliative RT courses were delivered to patients with bone metastases during the last 2 weeks, or last 2-4 weeks of their life, respectively in a large population based, publicly funded provincial RT program. Patients with lung and gastrointestinal cancers, or those receiving RT to their spine or extremity, were most likely to receive RT near the end of their life. Appropriately, longer multiple fraction (MF) RT courses were utilized less frequently for patients near their end of life.

Our finding of a 4 and $10 \%$ utilization of palliative RT for bone metastases in last 2 or 2-4 weeks of life, though on the low end, are consistent with previous literature. The reported overall palliative RT utilization rates during the last 2 weeks of life are in the range of $2.2-14 \%$ $[2,12-16]$. Our relatively lower utilization rates of palliative RT for bone metastases in this study could be multifactorial, including accurate prognostication by 
Table 1 Baseline patient, treatment, and provider characteristics

\begin{tabular}{|c|c|c|c|}
\hline & & Proportion & Proportion \\
\hline & & (Overall) & (Last 2 weeks of life) \\
\hline & & $\begin{array}{l}\text { RT course, } \\
n=16,898\end{array}$ & $\begin{array}{l}\text { RT course, } \\
n=709\end{array}$ \\
\hline Age (years) & $<51$ & $8.1 \%$ & $8.3 \%$ \\
\hline & $51-70$ & $44.2 \%$ & $45.8 \%$ \\
\hline & $>70$ & $47.7 \%$ & $45.8 \%$ \\
\hline Male & & $50.2 \%$ & $47.5 \%$ \\
\hline Primary tumour & Prostate & $19.0 \%$ & $10.2 \%$ \\
\hline & Breast & $23.4 \%$ & $7.3 \%$ \\
\hline & Lung & $22.4 \%$ & $42.0 \%$ \\
\hline & Hematological & $11.2 \%$ & $8.0 \%$ \\
\hline & $\mathrm{Gl}$ & $7.8 \%$ & $12.8 \%$ \\
\hline & others & $16.2 \%$ & $19.6 \%$ \\
\hline Skeletal metastasis & Spine & $42.2 \%$ & $49.4 \%$ \\
\hline & Pelvis & $28.6 \%$ & $23.6 \%$ \\
\hline & Extremity & $17.1 \%$ & $17.9 \%$ \\
\hline & Ribs & $8.1 \%$ & $6.6 \%$ \\
\hline & Sternum & $1.7 \%$ & $0.4 \%$ \\
\hline & Skull & $2.3 \%$ & $2.1 \%$ \\
\hline SFRT & & $49.2 \%$ & $64.2 \%$ \\
\hline BCCA centre & Abbotsford & $5.6 \%$ & $5.9 \%$ \\
\hline & Kelowna & $19.1 \%$ & $15.1 \%$ \\
\hline & Surrey & $16.3 \%$ & $18.6 \%$ \\
\hline & Vancouver & $35.8 \%$ & $33.7 \%$ \\
\hline & Victoria & $23.2 \%$ & $26.7 \%$ \\
\hline
\end{tabular}

SFRT single fraction radiation therapy, $B C C A$ british columbia cancer agency
Table 2 Clinical and provider characteristics associated with the use of palliative RT utilization in the last 2 weeks of life

\begin{tabular}{|c|c|c|c|}
\hline Characteristic & & $\begin{array}{l}\text { Proportion who } \\
\text { received RT in the } \\
\text { last } 2 \text { weeks of life }\end{array}$ & $P$ value \\
\hline \multirow[t]{3}{*}{ Age (years) } & $<51(n=1364)$ & $5.0 \%$ & \multirow[t]{3}{*}{0.27} \\
\hline & $51-70(n=7477)$ & $4.2 \%$ & \\
\hline & $>70(n=8057)$ & $4.0 \%$ & \\
\hline Male $(n=8491)$ & & $4.0 \%$ & 0.14 \\
\hline \multirow[t]{6}{*}{ Primary tumour } & Prostate $(n=3218)$ & $2.2 \%$ & \multirow[t]{6}{*}{$<0.001$} \\
\hline & Breast $(n=3959)$ & $1.3 \%$ & \\
\hline & Lung ( $n=3777)$ & $7.9 \%$ & \\
\hline & Hematological ( $n=1887)$ & $3.0 \%$ & \\
\hline & Gastrointestinal $(n=1319)$ & $6.9 \%$ & \\
\hline & Other $(n=2738)$ & $5.1 \%$ & \\
\hline \multirow{6}{*}{$\begin{array}{l}\text { Skeletal } \\
\text { metastasis }\end{array}$} & Spine $(n=7134)$ & $4.9 \%$ & \multirow[t]{6}{*}{$<0.001$} \\
\hline & Pelvis $(n=4826)$ & $3.5 \%$ & \\
\hline & Extremity ( $n=2897$ ) & $4.4 \%$ & \\
\hline & Ribs $(n=1362)$ & $3.5 \%$ & \\
\hline & Skull ( $n=393)$ & $3.8 \%$ & \\
\hline & Sternum $(n=286)$ & $1.0 \%$ & \\
\hline \multirow[t]{5}{*}{ BCCA centre } & Abbotsford $(n=946)$ & $4.4 \%$ & \multirow[t]{5}{*}{0.01} \\
\hline & Kelowna ( $n=3221$ ) & $3.3 \%$ & \\
\hline & Surrey $(n=2750)$ & $4.8 \%$ & \\
\hline & Vancouver $(n=6056)$ & $3.9 \%$ & \\
\hline & Victoria $(n=3925)$ & $4.8 \%$ & \\
\hline
\end{tabular}

$R T$ radiation therapy, $B C C A$ british columbia cancer agency

treating physicians, a lack of financial incentive to offer $\mathrm{RT}$ in this publicly funded system, or patient's choice to decline treatment $[10,17]$ Unfortunately, this cannot be assess in a retrospective study design.

Other authors state that the choice to offer palliative RT should be guided by life expectancy, though may also be influenced by a patient's site of primary disease or

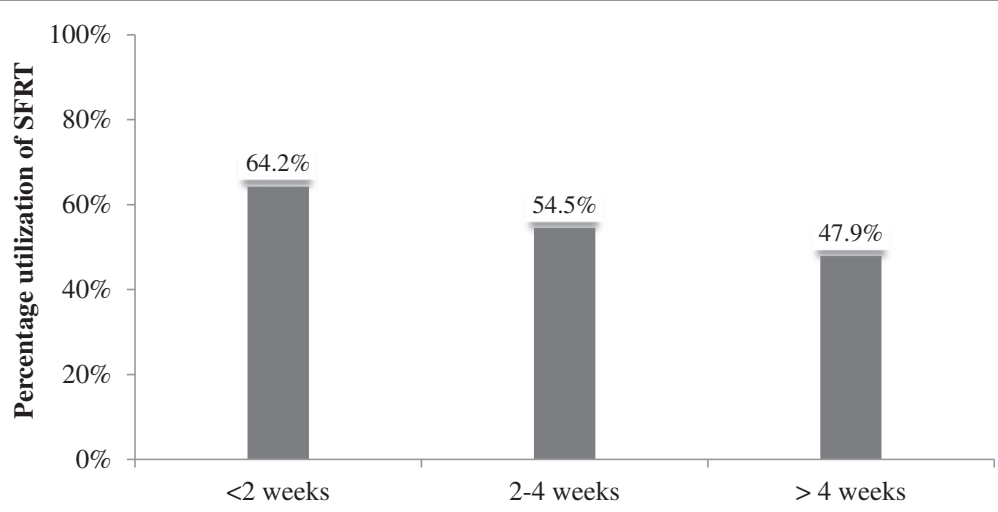

Time (from last palliative RT to death)

Fig. 1 Percentage utilization of single fraction radiation therapy (SFRT), by time from last course of RT to death 
Table 3 Multivariable logistic regression analysis on palliative RT utilization in the last 2 weeks of life

\begin{tabular}{|c|c|c|c|c|}
\hline \multicolumn{2}{|c|}{ Characteristic } & $\begin{array}{l}\text { Odds ratio to } \\
\text { receive } R T \text { in last } \\
2 \text { weeks of life } \\
\text { (>1 favors RT) }\end{array}$ & $\begin{array}{l}95 \% \\
\text { confidence } \\
\text { interval }\end{array}$ & $\begin{array}{l}P \\
\text { value }\end{array}$ \\
\hline \multicolumn{2}{|c|}{ Age of patient (continuous) } & 0.99 & $0.99-1.00$ & 0.41 \\
\hline \multirow{2}{*}{$\begin{array}{l}\text { Patient } \\
\text { gender }\end{array}$} & Female & Reference & & \\
\hline & Male & 0.87 & $0.74-1.01$ & 0.07 \\
\hline \multirow{6}{*}{$\begin{array}{l}\text { Primary } \\
\text { tumour }\end{array}$} & Prostate & Reference & & \\
\hline & Breast & 0.57 & $0.40-0.82$ & 0.002 \\
\hline & Lung & 3.72 & $2.86-4.84$ & $<0.001$ \\
\hline & Haematological & 1.29 & $0.91-1.85$ & 0.15 \\
\hline & Gastrointestinal & 3.33 & $2.42-4.58$ & $<0.001$ \\
\hline & Others & 2.35 & $1.76-3.14$ & $<0.001$ \\
\hline \multirow{6}{*}{$\begin{array}{l}\text { Skeletal } \\
\text { metastasis }\end{array}$} & Spine & Reference & & \\
\hline & Pelvis & 0.67 & $0.55-0.81$ & $<0.001$ \\
\hline & Extremity & 0.87 & $0.71-1.08$ & 0.21 \\
\hline & Ribs & 0.66 & $0.48-0.90$ & 0.01 \\
\hline & Sternum & 0.22 & $0.07-0.69$ & 0.01 \\
\hline & Skull & 0.85 & $0.49-1.45$ & 0.55 \\
\hline \multirow{5}{*}{$\begin{array}{l}\text { BCCA } \\
\text { centre }\end{array}$} & Vancouver & Reference & & \\
\hline & Abbotsford & 1.14 & $0.81-1.59$ & 0.46 \\
\hline & Kelowna & 0.86 & $0.68-1.09$ & 0.20 \\
\hline & Surrey & 1.29 & $1.09-1.62$ & 0.03 \\
\hline & Victoria & 1.34 & $1.09-1.62$ & 0.005 \\
\hline
\end{tabular}

$R T$ radiation therapy, $B C C A$ british columbia cancer agency

area requiring palliation [18-20]. Indeed, we found a significant variation in the use of RT near the end of life, based on primary tumor site (most common for lung and GI cancer) and site requiring palliative RT (most common for spine and extremity) (Tables 2 and 3). We hypothesize the higher use of end of life RT in lung and GI cancers may be a factor of their worse prognosis, where treating physicians may be less accurately predicting their poor prognosis. Perhaps the use of prognostic indices could decrease the use of potential futile RT near the end of life, which unfortunately we cannot assess within this retrospective study [5, 21-23].

Furthermore, we hypothesize that the more frequent use of RT near the end of life for spine and extremity metastases is related to the severity of the symptoms they produce. As an example, physicians are likely more reluctant to withhold RT for a spinal cord compression or a fractured extremity, than they are for a fractured rib or painful sternum, irrespective of prognosis. We propose that physicians adopt more uniform use of prognostic tools before offering palliative RT, as it is unlikely that patients receiving RT in the last 2 weeks, even if they are suffering from a spinal cord compression or fractured extremity, given the required 2-4 weeks to see a clinical benefit. Finally, a more convenient and appropriate single fraction RT (SFRT) was prescribed in $64 \%$ of the palliative RT courses to patients who died within 2 weeks of receiving RT. Multiple studies have shown and confirmed the benefit and efficacy of SFRT near end of life $[18,24,25]$.

This study should be interpreted in the context of its strengths and limitations. Unfortunately, due to the retrospective nature of the study, information on patients' cultural beliefs, their decision about treatment, hospital admission, or whether the bone metastases were complicated by fracture or neurological compromise was not available. Further, the efficacy of palliative RT in terms of pain control was also not analyzed due to the nature of study design. However, this population-based provincial study is relatively free from referral and selection bias, and choice of RT prescription is not influenced by physician remuneration or patient's ability to pay in this public healthcare model with physicians on salary.

\section{Conclusions}

This population-based analysis found that only 4 and $10 \%$ of patients with bone metastases received radiotherapy during the last 2 weeks, or 2-4 weeks of their life, respectively. Radiotherapy near the end of life was used most frequently for lung and gastrointestinal cancers, potentially as a result of their inherently worse prognosis which physicians are not accurately predicting. End of life RT was also used frequently for patients receiving RT to the spine or extremity, which we hypothesize, is because of the potential severity of symptoms in these sites, such as spinal cord compression or fractured extremity. However, given the likely futility in offering RT during the last two weeks of life, our research supports the more widespread adoption of prognostic tool use prior to prescribing palliative RT. Appropriately, the use of multiple fractions palliative RT course was less frequently used in patients with a shorter lifespan.

\section{Abbreviations}

RT: radiotherapy; BCCA: BC Cancer Agency; HSDA: health service delivery area; CAIS: cancer agency information system; OR: odds ratio; Cl: confidence interval; SFRT: single fraction radiation therapy; Gl: gastrointestinal.

\section{Competing interests}

We have read and understood BMC Palliative Care's policy on disclosing conflicts of interest and declare that we have none.

\section{Authors' contributions}

RAO: study conception; data acquisition; conducted the statistical analysis; drafting and revision of the manuscript; MST, MB, AK: contributed to data analysis, drafting and revising the draft manuscript critically for important intellectual content All of the authors approved the final version submitted for publication. All authors read and approved the final manuscript. 


\section{Acknowledgements}

This work was supported in part from funding from the University of British Columbia and the University of Northern British Columbia.

\section{Author details}

${ }^{1} \mathrm{BC}$ Cancer Agency-Centre for the North, Prince George, Canada. ${ }^{2}$ University of Northern British Columbia, Prince George, Canada. ${ }^{3}$ University of British Columbia, Vancouver, Canada.

Received: 19 June 2015 Accepted: 7 December 2015

Published online: 10 January 2016

\section{References}

1. Janjan NA. An emerging respect for palliative care in radiation oncology. J Palliat Med. 1998;1:83-8.

2. Guadagnolo BA, Liao KP, Elting L, Giordano S, Bucholz TA, Ya-Chen TS. Use of radiation therapy in the last 30 days of life among a large populationbased cohort of elderly patients in the United States. J Clin Oncol. 2013;31: 80-7.

3. Chow E, Harris K, Fan G, Tsao M, Wai MS. Palliative radiotherapy trials for bone metastases: A systematic review. J Clin Oncol. 2007;25:1423-36.

4. Hartsell WF, Scott CB, Bruner DW, Scarantio CW, Ivker RA, Roach Mack, et al. Randomized trial of short- versus long-course radiotherapy for palliation of painful bone metastases. J Natl Cancer Inst. 2005;97:798-804.

5. Jones JA, Lutz ST, Chow E, Johnstone PA. Palliative radiotherapy at the end of life: a critical review. CA Cancer J Clin. 2014:64:296-310.

6. Earle CC, Landrum MB, Souza JM, Neville BA, Weeks JC, Ayanian JZ. Aggressiveness of cancer care near the end of life: Is it a quality-of-care issue? J Clin Oncol. 2008;26:3860-6.

7. Ho TH, Barbera L, Saskin R, Hong L, Neville BA, Earle CC. Trends in the aggressiveness of end-of-life cancer care in the universal health care system of Ontario, Canada. J Clin Oncol. 2011;29:1587-91.

8. Murphy JD, Nelson LM, Chang DT, Mell LK, Le QT. Patterns of care in palliative radiotherapy: a population-based study. J Oncol Pract. 2013;9: e220-7.

9. Barthelemy N, Jansen N, Gennigens C, Delgaudine M, Coucke PA. Does Radiotherapy have a role in end-of-life care? Rev Med Liege. 2012;67: 128-32.

10. Olson RA, Tiwana MS, Barnes M, Kiraly A, Beecham K, Miller S, et al. Use of single- versus multiple-fraction palliative radiation therapy for bone metastases: population-based analysis of 16,898 courses in a Canadian province. Int J Radiat Oncol Biol Phys. 2014;89:1092-9.

11. Jackson SM, Tyldesley S, Baerg B, Olivotto IA. Are the creation and maintenance of databases in healthcare worthwhile? An example of a unique, population-based, radiation therapy database. Healthc Q. 2012 15:71-7.

12. Kress MA, Jensen RE, Tsai HT, Lobo T, Satinsky A, Potosky AL. Radiation therapy at the end of life: a population-based study examining palliative treatment intensity. Radiat Oncol. 2015;10:15.

13. Ellsworth SG, Alcorn SR, Hales RK, McNutt TR, DeWeese TL, Smith TJ. Patterns of care among patients receiving radiation therapy for bone metastases at a large academic institution. Int J Radiat Oncol Biol Phys. 2014;89:1100-5.

14. Kapadia NS, Mamet R, Zornosa C, Niland JC, D'Amico TA, Hayman JA. Radiation therapy at the end of life in patients with incurable nonsmall cell lung cancer. Cancer. 2012;118:4339-45.

15. Yeung $H$. Palliative radiation before hospice: the long and the short of It. In: Johnstone C, Lutz ST, editors. External beam radiotherapy and bone metastases, Annals palliative medicine. San Diego: American Academy of Hospice and Palliative Medicine Annual Assembly; 2014. p. 114-22.

16. Toole M, Lutz S, Johnstone PA. Radiation oncology quality: aggressiveness of cancer care near the end of life. J Am Coll Radiol. 2012:9:199-202.

17. Olson RA, Tiwana M, Barnes M, Cai E, McGahan C, Roden K, et al. Impact of using audit data to improve the evidence-based use of single-fraction radiation therapy for bone metastases in British Columbia. Int J Radiat Oncol Biol Phys. 2016;94:40-7. doi:10.1016/j.jijobp.2015.06.044.

18. Lutz S, Berk L, Chang E, Chow E, Hahn C, Hoskin P, et al. Palliative radiotherapy for bone metastases: An ASTRO evidence-based guideline. Int J Radiat Oncol Biol Phys. 2011;79:965-76.
19. Roos DE. Continuing reluctance to use single fractions of radiotherapy for metastatic bone pain: an Australian and New Zealand practice survey and literature review. Radiother Oncol. 2000;56:315-22.

20. Crellin AM, Marks A, Maher EJ. Why don't British radiotherapists give single fractions of radiotherapy for bone metastases? Clin Oncol. 1989;1:63-6.

21. Krishnan M, Temel J, Wright A, Bernacki R, Selvaggi K, Balboni T. Predicting life expectancy in patients with advanced incurable cancer. J Support Oncol. 2013;11:68-74.

22. Chow E, Davis L, Panzarella T, Hayter C, Szumacher E, Loblaw A, et al. Accuracy of survival prediction by palliative radiation oncologists. Int J Radiat Oncol Biol Phys. 2005;61:870-3.

23. Fairchild A, Debenham B, Danielson B, Huang F, Ghosh S. Comparative multidisciplinary prediction of survival in patients with advanced cancer. Support Care Cancer. 2014;22:611-7.

24. Lutz S, Korytko T, Nguyen J, Khan L, Chow E, Corn B. Palliative radiotherapy: when is it worth it and when is it not? Cancer J. 2010;16:473-82.

25. Hayman JA, Abrahamse PH, Lakhani I, Earle CC, Katz SJ. Use of palliative radiotherapy among patients with metastatic non-small-cell lung cancer. Int J Radiat Oncol Biol Phys. 2007;69:1001-7.

\section{Submit your next manuscript to BioMed Central and we will help you at every step:}

- We accept pre-submission inquiries

- Our selector tool helps you to find the most relevant journal

- We provide round the clock customer support

- Convenient online submission

- Thorough peer review

- Inclusion in PubMed and all major indexing services

- Maximum visibility for your research

Submit your manuscript at www.biomedcentral.com/submit 